\title{
STEPHEN HAWKING, LA CIVILIZACIÓN POSHUMANA Y EL HOMO GENETICUS.
}

\begin{abstract}
Eduardo Badía Serra ${ }^{1}$
Los problemas de la conciencia, de la comunicación de las sustancias y de la inteligencia artificial en el ámbito de la ciencia y de la filosofía, y el problema de la relación mente-cuerpo son sumamente complejos y se abordan desde diferentes posiciones. Con todo, se mantienen dentro del enfoque del humano enfrentado con la tecnología que el mismo ha creado.
\end{abstract}

The issues of consciousness, of the communications of substances, and of the artificial intelligence in science and in philosophy, and the issue of the relation between mind and body are highly complex; they are discussed from different perspectives. Nonetheless, all the above are within the conceptualization of the human beings facing the technology they have created by themselves

\section{LAS CIVILIZACIONES ESPACIALES Y POSHUMANAS}

Para Russell, la conciencia no es precisamente el asunto más importante para el hombre, no es algo esencial en él, y por ello, aunque lo aborda en relación con el problema de la mente, este matemático y filósofo británico prefiere hablar de inteligencia. Koch enfoca el enfrentamiento entre la mente y el cerebro humano y las computadoras bajo una perspectiva eminentemente biológica, que es lo que en su opinión le falta a Penrose, y alrededor de los correlatos neurales de la conciencia. Roger Penrose, por su parte, rechaza la posibilidad de que la inteligencia artificial pueda crear conciencia y sustituir a la mente humana, y basa el accionar de ésta en un comportamiento mecánico-cuántico, de forma tal que con los conceptos de la física clásica no es posible llegar a comprender cómo funciona la mente, ya que los microtúbulos de Hamerof se comportan cuánticamente. Para Penrose, en el funcionamiento de la mente humana hay elementos no algorítmicos que no pueden darse en una computadora. Searle, por su parte, es un tanto menos definitivo, y aunque rechaza la inteligencia artificial fuerte, con lo cual a la vez rechaza el que la mente humana pueda ser sustituida por una computadora, sí piensa que la inteligencia artificial débil puede ser un instrumento que, sin pretender sustituir la mente humana y menos llegar a crear conciencia, puede se útil al hombre.

Pero hay otras posiciones que plantean un escenario muy diferente, y que señalan que el hombre, a menos que se modifique genéticamente y que pueda colonizar otros planetas o espacios universales, será superado por la inteligencia 
artificial y condenado a desaparecer como especie. En esta postura encontramos, entre otros, al gran físico teórico británico Stephen Hawking, quien, con algunos antecedentes que se expondrán someramente y junto a otros que comparten ahora mismo su posición en términos esenciales, ha expuesto una interesante teoría que comentaremos en este trabajo.

Hawking, (Oxford, enero de 1942), para algunos, el más famoso de los teóricos de la física vivo y el mayor cosmólogo viviente, es el titular de la cátedra lucasiana de matemáticas en Cambridge, Inglaterra, cátedra que ocuparan en su momento Isaac Newton y Paul Dirac. Ha contribuido, igual que Einstein, a la renovación de la física. Afectado, como se sabe, por una grave enfermedad progresiva que le ha recluido en una silla de ruedas, ha logrado sin embargo construir una inquietante imagen del universo. Entre sus libros y publicaciones más conocidas se encuentran: Historia del Tiempo. Del Big Bang a los Agujeros Negros; Agujeros Negros y Pequeños Universos, y otros ensayos; La Naturaleza del Espacio y del Tiempo, escrita junto con Roger Penrose; y El Universo en una Cáscara de Nuez. Hawking es considerado un icono de la ciencia actual, y sus opiniones y posiciones, muchas veces radicales y fuertes pero siempre bien fundamentadas, son respetadas y reconocidas sin discusión aún por sus opositores. De su posición en relación con los temas expuestos trataremos de hacer una exposición, comenzando por situar algunos antecedentes sobre estas ideas de las civilizaciones supertecnológicas, poshumanas, extraterrestres y del hombre modificado.

\section{ANTECEDENTES: LAS CIVILIZACIONES SUPERTECNOLÓGICAS Y EL HOMBRE MODIFICADO.}

Según nos dice Rubén Ríos, $(5,90-99)$, el primero en imaginarse una civilización supertecnológica fue probablemente el físico John Archibald Wheeler, (19112008), quien también acuñó el término agujero negro en la NASA, en 1969. Wheeler imaginó una civilización que abandonaba su estrella y emigraba a las cercanías de un agujero negro para apropiarse de la energía, eliminando sus desechos en él a contragiro de la rotación y utilizando la energía rotativa frenada por la basura, de modo que, desafiando la entropía, los residuos se convertían en energía. Como se dice, la vida de los agujeros negros es mayor que la de cualquier otra estrella y será el último proceso físico de importancia en desaparecer del universo, pero finalmente se disolverán en una sopa sombría de electrones y neutrinos. Antes de llegar a ese futuro remoto, dentro de unos dos mil o tres mil millones de años, los seres que habiten la Tierra tendrán que dejarla porque el Sol la incendiará y deberán colonizar otro planeta en la misma galaxia o en otra. Con tanto tiempo por delante, continúa Wheeler, la civilización tecnológica nacida en nuestros tiempos deberá resolver de algún modo su supervivencia en un universo que se muere. 
Wheeler fue un eminente físico teórico norteamericano, colaborador de Einstein, profesor de las más prestigiosas universidades norteamericanas, y compañero de Bohr y de Fermi en el desarrollo de la fisión nuclear. Las anteriores imaginaciones provienen de alguien que no ignoraba los grandes avances de la física y de la astronomía, y por lo tanto deben ser consideradas como imaginaciones serias, si se quiere, a pesar de sus asombrosas predicciones.

También Paul Davies, el conocido filósofo y cosmólogo británico, (Paul Davies, 1946, profesor de Filosofía Natural en la Universidad de Adelaida, Australia), participa de esta necesidad de que la especie humana resuelva de algún modo su supervivencia en un universo que se muere. Cita el mismo Ríos, $(5,90-99)$, que en su obra Los últimos tres minutos, Davies considera que esa necesidad llevará a que nuestros descendientes, en un futuro no muy lejano, no sean seres humanos sino criaturas biotecnológicas diseñadas genéticamente. Serán ellos los colonizadores planetarios que se imagina Wheeler, dice Ríos. Estos colonizadores planetarios necesitarán ser manipulados genéticamente, tanto física como psíquicamente, para adaptarlos a las características de los largos viajes galácticos y del planeta de su destino, o ser formados con óvulos fertilizados y congelados que serían incubados una vez llegaran a su destino. Estos seres ya no serían humanos, ni en su aspecto ni mentalmente, y probablemente no sean organismos vivos por completo sino una especie de materia orgánica mezclada con partes electrónicas o artificiales para que realice cierto tipo de funciones fisiológicas y cerebrales. Eso significa que se fabricarían componentes informáticos biológicos y redes neurales a partir del tejido cerebral, con lo que serían sustituidas las computadoras. Sería como el final de los límites entre lo vivo y lo muerto, lo artificial y lo natural, lo orgánico y lo inorgánico. Estamos, pues, ante la presencia futura de robots orgánicos genéticamente manipulados para explorar y colonizar la galaxia, los cuales permitirán la sobrevivencia de una humanidad forzada a mutarse a sí misma con el fin de afrontar la continuidad de la especie por todos los medios.

No se puede evitar considerar el hecho de que esta civilización supertecnológica afrontará también una crisis de energía, debido a que aún con la solución de Wheeler no es posible ignorar que siempre habrá un resto de energía disipada por la actividad misma de eliminar los desechos, debido a la imposibilidad de superar la velocidad de la luz. Para superar esta limitación, que llevaría siempre a la destrucción de esa civilización supertecnológica de no ser superada, el físico Freeman Dyson propone como solución el que dicha civilización hiberne por larguísimos períodos para poder mantenerse a un ritmo de procesamiento de la información compatible con la declinación del universo. En la fase de sueño se disiparía el calor acumulado durante la hibernación mientras se acumula energía para utilizarla en la próxima fase de vigilia. El universo casi se eternizaría a través de la oscuridad final. Hawking ha propuesto para evitar lo anterior, extraer energía de un agujero negro pero no aplicarla al efecto de su 
contragiro sino a la llamada radiación de Hawking, con lo que se podría evitar la hibernación y arrojar los desechos al agujero negro, lo que lo haría más frío, más grande, y suspendería su colapso final.

Pareciera, pues, que en un universo en expansión eterna, la crisis energética es un problema continuo al que tendría que enfrentarse cualquier civilización. La solución de Dyson es aparentemente sencilla, como se ha visto: reducir la tasa metabólica en períodos de hibernación cada vez más numerosos y largos. Puesto que el tiempo de expansión es eterno, por muy lentos que sean los procesos metabólicos, el número de ellos pudiera divergir, y el tiempo subjetivo de la vida podría así ser eterno. ¡La vida podría existir para siempre y tener un número de pensamientos infinitos! Esa es la conclusión, simple y a la vez tremenda. Hernández, en su ensayo Ciencia y Esperanza, (6,10/23), así lo expone.

Sin embargo, algunos problemas se presentan con la hipótesis de Dyson. El primero, la imposibilidad de construir despertadores que operen con precisión para tiempos cada vez mayores, a la vez que consumir menos y menos energía, lo cual contradice el Principio de Incertidumbre de Heisemberg. Segundo, los organismos podrían colectar sólo una cantidad finita de materia y energía, por lo que sólo es posible una capacidad de memoria finita y el procesamiento de una cantidad finita de información. $(6,10 / 23)$. Una tercera dificultad es probablemente más complicada y más difícil de resolver: en un universo con una expansión acelerada y dominada por una constante cosmológica, como el que expone el modelo de la expansión indefinida, (una de las Analogías de Friedmann), el valor medido de dicha constante introduce una especie de efecto gravitatorio repulsivo que obliga al universo a acelerar su expansión. Un universo con constante cosmológica posee un límite inferior de temperatura que puede ser alcanzada, impuesto por un baño de radiación térmica conocida como Radiación de Gibbons-Hawking, análoga a la radiación térmica emitida por un agujero negro. La vida en tal escenario estaría condenada a la extinción al carecer en algún momento de un foco frío que le permita realizar trabajo útil. El universo terminaría entonces con un baño térmico de radiación a temperatura de unos $10-29^{\circ} \mathrm{K}$. Ahora bien, para que ello ocurra, se necesitarían tiempos del orden de $10^{50}-10^{100}$ años, lo que en términos humanos equivale a una auténtica eternidad.

¿De qué se habla con estas, hasta cierto punto, increíbles hipótesis? ¿Quedará algún lugar donde ir cuando se haya consumido el universo entero? ¿Será, quizá, que la física teórica ha caído en niveles tan altos de especulación que pareciera realmente que se trata de posiciones más bien metafísicas? Como decía Niels Bohr, Es difícil hacer predicciones.....sobre todo si se trata del futuro. Sin embargo, el problema aquí es que tales predicciones, fantásticas como las que más, provienen de eminentes científicos e investigadores, cuyas 
hipótesis, en otros casos, han sido comprobadas y aceptadas ya por la ciencia con un verdadero carácter de ley científica, por lo que no pueden dejar de considerarse. Respondiendo a Bohr, para el caso, una frase anónima dice, por ello, que me interesa el futuro, porque pienso pasar allí el resto de mis días, aunque este interés no hable de predecirlo sino simplemente de interesarse por él

Y si el universo no continuara expandiéndose ilimitadamente y se diera el caso del universo en expansión - contracción, de acuerdo a lo que indica otra de las analogías de Friedmann, la que corresponde a un espacio riemanniano, la situación se complicaría aun más puesto que cerca del big crunch la vida inteligente sería muy difícil y no podría sobrevivir. Sólo si en el momento del big crunch, y en el muy difícil caso de que algún ser supertecnológico llegue hasta ese momento final, habrá alguna esperanza de vida para él, porque, especula Davies, si el superser logra seguir las oscilaciones infinitas de la contracción, podrá enfrentar la implosión a una velocidad infinita de pensamiento y el tiempo subjetivo se dilataría también al infinito. Los segundos finales se estirarían eternamente en esa mente capaz de sobrevivir simulando una realidad virtual limitada. $(5,90-99)$.

Hay muchas más especulaciones físicas sobre este asunto del futuro del universo, y con ello, de la humanidad. Cito sólo, como ejemplos, los universosburbuja antrópicos del físico ruso Andréi Linde, los universos crías del mismo Davies y los universos de bolsillo de Guth.

\section{HAWKING Y EL HOMO GENETICUS}

A Hawking no parecen agradarle especulaciones como las anteriores. Él piensa que el hombre debe asegurar los viajes espaciales con el objeto de colonizar mundos fuera del sistema solar. La humanidad está condenada a desaparecer antes de que finalice el milenio por los efectos de un virus devastador, natural o artificial, o por catástrofes ecológicas, o por la inteligencia artificial, siendo ésta la que probablemente desencadenará tal final antes que las otras causas posibles; y ello, a menos que los hombres colonicen el espacio o se rediseñen genéticamente, ha dicho tajantemente al periódico Daily Telegraph y a la revista Focus. Probablemente el gran físico británico se estaba refiriendo al tercer milenio.

Barrow, (John D. Barrow, Londres, 1952, profesor de Física Teórica en Cambridge, Inglaterra, uno de los astrofísicos más reconocidos en la actualidad), conjuntamente con Fran J. Tipler, en The Anthropic Cosmological Principle, 1985, y otras obras, aceptaba la posibilidad, al menos teórica, de que el hombre pudiera conquistar la galaxia entera en períodos de tiempo del orden de unos pocos millones de años, lo cual aseguraría la subsistencia segura de la especie 
humana por al menos otros diez eones. Según Barrow, las posibilidades de la civilización a muy largo plazo descansan en los hombros de la cosmología.

Al contrario de su amigo y colega Roger Penrose, él cree que las máquinas inteligentes sí pueden superar a la especie humana, y basa su afirmación en que el poderío de la inteligencia artificial se duplica cada dieciocho meses, según lo apunta la Ley de Moore. Ello posibilita el que llegue a desarrollar una mente propia y asuma el control del mundo en un plazo relativamente corto. La única posibilidad de que esto ocurra es que el hombre se modifique biogenéticamente, complejando su ADN, y ello debe hacerse fusionando los sistemas electrónicos y los humanos, a fin de que la inteligencia artificial ayude a mejorar los cerebros biológicos en vez de revelarse contra ellos. Y como la humanidad, la especie humana, sólo logrará sobrevivir cuando haya encontrado planetas habitables en otras estrellas, es necesario también desarrollar las tecnologías de colonización del espacio.

¿Ciencia ficción? ¿Fantaciencia? Veamos un poco.

En primer lugar, detallemos un poco en qué consiste esta famosa Ley de Moore. Esta ley, de naturaleza empírica y sin ningún soporte teórico, fue formulada por el co-fundador de Intel Gordon E. Moore el 19 de abril de 1965. Moore afirmó entonces que el número de transistores por pulgada en un circuito integrado se duplicaba aproximadamente cada dos años, por lo que la tecnología tenía futuro. En 1975 modificó su propia ley, atenuando el ritmo de crecimiento, y expresando que su ley dejaría de cumplirse en un período de 10 a 15 años a partir del año 2007. Esto provoca, de acuerdo con las leyes del mercado, el hecho de que los precios de las computadoras bajarían a medida que la ley se cumpliera. La Ley de Moore se cumple actualmente tanto como falla. Su ley se ha seguido cumpliendo aun después del año 2007, pero la velocidad de crecimiento que expresa aparentemente se ha atenuado. La Ley de Moore no tiene un carácter estrictamente científico. Es sólo de carácter observacional, pero es aceptada y sus aplicaciones se comprueban con bastante precisión. Sin embargo, la Ley de Moore se refiere sólo al hardware, y ello provoca una de las críticas más fuertes en su contra. La mejor forma de expresión de estas críticas la ha dado Nathan Myhrvold, quien, de forma ingeniosa ha expresado su Ley de Nathan, que establece que el software crece más rápidamente que la misma Ley de Moore, y que por ello es que tenemos Ley de Moore. $(7,146)$.

Hawking precisamente basa su hipótesis en dicha Ley de Moore. El ADN, dice, evoluciona muy lentamente. Comenzó, hace millones de años, evolucionando a razón de un bit cada cien años. Ahora lo hace a razón de un bit por año. Pero esto es aun muy lento, y la biotecnología es quien puede modificar esta velocidad de crecimiento aumentándola a voluntad. Por lo tanto, Hawking propone que la 
mejor forma de combatir la inteligencia artificial es uniéndose a ella y utilizando sus propias potencialidades para diseñar y crear un hombre nuevo modificado genéticamente. Si la humanidad no se autodestruye, dice, y se esparce por el sistema solar y luego por las estrellas más próximas, sobrevivirá. Para ello, la modificación genética del ser humano es indispensable. La inteligencia artificial puede ayudar mucho a lograr tal modificación.

Esta idea del hombre modificado no es nueva ni es de la ciencia. Se habla ya de ella en la filosofía moderna y en la contemporánea. Pero se expresa ya con algún detalle a partir del siglo anterior. El Dr. Helmer, aplicando la técnica de Delfos, hablaba ya de lo cambios que la tecnología provocaría en la especie humana, y pronosticaba que, para el año 2025, serían posibles algunas realidades tales como la interacción electromecánica directa entre el hombre y la computadora, el control químico del envejecimiento para prolongar la vida, y el desarrollo de drogas para aumentar la inteligencia.

En el cuadro siguiente se exponen los pronósticos del Dr. Helmer:

Pronóstico de los avances en la relación Hombre-Tecnología obtenidos mediante la Técnica de Delfos por el Dr. Helmer

\author{
Período \\ Pronóstico \\ 1965-1985 Nuevos órganos mediante trasplantes o prótesis. Ya se ha dado. \\ 1965-1985 Control efectivo y real dae la fecundidad. Ya se ha dado. \\ 1975-1990 Órganos artificiales de plástico. Ya se ha dado. \\ 1975-1990 Componentes electrónicos implantados. Ya se ha dado. \\ 1980-2000 Administración de drogas no narcóticas para cambiar personalidad. \\ Ya se ha dado. \\ 1980-2000 Vida artificial primitiva en forma de autoduplicación de moléculas. \\ Ya se ha dado. \\ 1985-2025 Interacción electromecánica directa entre un cerebro y una computadora. \\ En proceso. \\ 1990-2010 La ingeniería genética controla algunos defectos artificiales. En proceso. \\ 1990-2030 Control químico del envejecimiento para prolongar la vida. En proceso. \\ 1995-2025 Productos bioquímicos para estimular el crecimiento de nuevos órganos y \\ miembros. En proceso.
}

1995-2025 Desarrollo de drogas para aumentar la inteligencia. En proceso.

En síntesis, pues, ¿cuáles son las predicciones, o más bien las propuestas de Hawking?: 
Lo que él trata de decir es que hay que aumentar la velocidad de la evolución del hombre, y no sólo aumentar la velocidad sino también direccionar dicha evolución sin tener que esperar los largos períodos de la evolución natural. Esto es, hacer más complejo, por medios no naturales, el DNA humano.

Hawking está consciente de que la creación del hombre modificado originará problemas sociales y políticos $(3,165)$. Realmente, él no defiende la ingeniería genética humana como un desarrollo deseable, sino que reconoce que es algo que sucederá, querámoslo o no, a menos que se instaure un orden mundial de carácter totalitario que lo impida. $(3,165)$. Habrá que tratar, pues, con él, y lo mejor entonces es prepararse y ayudar.

\section{HAWKING Y LA INTELIGENCIA ARTIFICIAL}

Hemos dicho que Hawking basa sus predicciones sobre la mente humana y las computadoras en los resultados hasta hoy obtenidos por la Ley de Moore. Pero en El Universo en una Cáscara de Nuez, $(3,165)$, afirma que si bien las computadoras avanzan a mayor velocidad que la mente, siguiendo precisamente dicha ley, no parecen dar muestras de inteligencia. Y aunque la velocidad de desarrollo de las computadoras deberá atenuarse en algún momento, siguiendo siempre la Ley de Moore aunque no señalando año en particular a partir del cual esto ocurra, para ese momento ya habrán alcanzado la complejidad del cerebro y de la mente, si es que estos no se modifican genéticamente. Esa es, precisamente, su gran preocupación.

Hawking hace un razonamiento de una naturaleza muy simple y lógica: Si los hombres son inteligentes, presumiblemente podrán diseñar computadoras que eventualmente tengan incluso mayor complejidad e inteligencia que ellos mismos, dice $(3,167)$. ¿Hasta cuánto es el límite de crecimiento de la complejidad de este crecimiento? Desde el lado biológico, el límite de la inteligencia humana lo fija el tamaño del cerebro, y este a su vez se limita al tamaño del canal de nacimiento. Si en los años por venir, la posibilidad de que nazcan y crezcan niños afuera del cuerpo humano se concreta, (crecimiento de embriones afuera del cuerpo de la mujer), esta limitación desaparecerá. Ahora bien, el crecimiento en la complejidad de la inteligencia se hará siempre e inevitablemente a expensas de su velocidad, y viceversa. No podrá entonces crecer la inteligencia y la vez la complejidad. O lo uno, o lo otro (3, 167-168).

En el lado electrónico se presenta la misma relación inversa complejidad/ velocidad; pero la gran diferencia es que en este caso, las señales son eléctricas y viajan a la velocidad de la luz, que es mucho mayor que las señales químicas del caso anterior, (lado biológico). Es la velocidad de la luz el límite último entonces de la velocidad de crecimiento de la inteligencia artificial $(3,168)$. Pudiera intentarse aumentar tanto la velocidad como la complejidad del 
crecimiento de la inteligencia artificial, haciendo, por ejemplo, más pequeños los circuitos, pero en este caso aparecería otro nuevo límite, la naturaleza atómica de la materia; o también, copiando la estructura del cerebro humano. Este no tiene una unidad central de procesamiento, como un CPU, sino que actúa mediante millones de procesadores actuando todos juntos y al mismo tiempo. Este sistema masivo de procesamiento paralelo será, para Hawking, el futuro de la inteligencia electrónica $(3,168-169)$. Como puede verse, esta esperanza de Hawking de que las computadoras puedan procesar paralelamente, es, contrariamente, una de sus más fuertes limitaciones, según señalan otros científicos e investigadores.

\section{HACIA UN INTENTO DE RESUMEN}

¿Cómo podría intentar resumirse la posición de Stephen Hawking en relación al futuro de la especie humana y a la posición del hombre ante el desarrollo de la inteligencia artificial? Intento una exposición de manera esquemática:

1) Implantes neurales pueden permitir una mucha más rápida interconexión entre el cerebro y las computadoras, superando la barrera que separa a la inteligencia biológica de la inteligencia electrónica.

2) Dentro de algunas décadas, muchos hombres elegirán vivir una existencia virtual en la NET, formando comunidades y relaciones cibernéticas.

3) El genoma humano será completamente conocido, y el DNA será significativamente más complejo en su estructura.

4) En los próximos pocos cientos de años, la ingeniería genética humana podrá reemplazar a la evolución biológica, rediseñando las razas humanas y reposicionando completamente nueva cuestiones éticas.

5) Los viajes espaciales más allá de nuestro sistema solar requerirán probablemente ya sea humanos modificados genéticamente o probadas computadoras controladas por humanos.

Hawking termina haciendo ver que la inteligencia no es lo esencial para la sobrevivencia en los seres vivos. Las bacterias, ejemplifica, saben vivir y sobrevivir muy bien sin inteligencia, y nos sobrevivirán en caso de que nuestra inteligencia provocara una guerra nuclear que limpiara el planeta, incluyéndonos a nosotros. $(3,171)$. 


\section{REFLEXIÓN PROPIA}

No es rechazable el que la ciencia y la tecnología hagan públicos sus avances, expongan las posiciones de los científicos y de los tecnólogos, y entren en el difícil y oscuro campo de la predicción. Pero si bien la ciencia debe entrar en el estudio sobre el destino final del hombre y del universo, ello no debe hacerlo con un carácter escatológico. Como dice el mismo Hawking, viajar en el tiempo no es teóricamente posible, pues si lo fuera, ya estarían aquí contándonos al respecto. En el tiempo sólo se viaja, como decía Einstein, haciéndolo a una velocidad de una hora por hora.

Es necesario encontrar formas de manejar el futuro, y más aún si en ello se juega la vida del hombre y de la especie misma, pues parodiando a G. C. Williams, la evolución no actúa en criaturas que ya están muertas. Yo prefiero pensar, como Bohr, en que sobre el futuro valen poco las predicciones.

Esperemos un tanto. El hombre debe detener él mismo el avance tecnológico y limitar su velocidad a la misma velocidad de la mente humana. Eso sí puede hacerlo. La inteligencia artificial, pueda o no sustituir a la mente humana y pueda o no llegar a formar conciencia, es creación del hombre. No es racional pensar que éste llegue a crear una máquina que pudiera en algún momento servir para su misma autodestrucción. Efectivamente, como decía John von Newman durante una conferencia pronunciada en Princeton en 1948, y contestando a una pregunta que le hiciera alguien desde el auditorio: Usted insiste en que hay cosas que una máquina no puede hacer. Si me dice de forma precisa lo que una máquina no puede hacer, entonces yo siempre puedo hacer una que haga exactamente eso mismo que usted ha dicho. Probablemente el hombre pueda hacer una máquina que pueda incluso sustituirle; pero en él está el hacerla o no, y ello será siempre su decisión.

Lo mejor es, pues, viajar a una velocidad de una hora por hora, como decía Einstein. Así, iremos seguros, y podremos hacerlo confiados.

\section{BIBLIOGRAFÍA}

1) Stephen Hawking, Historia del Tiempo. Del Big Bang a los Agujeros Negros, Editorial Crítica, Grupo Editorial Grijalbo, México, 1988.

2) Stephen Hawking, Agujeros Negros y Pequeños Universos (y otros ensayos), Plaza \& Janes Editores, Tribuna, Barcelona, 1994. 
3) Stephen Hawking, The Universe in a Nutshell, Bantam Books, New York, November 2001.

4) Stephen Hawking, La Teoria del Tutto. Origine e Destino dell 'Universo, BUR, Scienza, terza edizione, Milano, ottobre 2006.

5) Rubén H. Ríos, Stephen Hawking y el Destino del Universo, Campo de Ideas, Primera Edición en Argentina, octubre 2005.

6) Pedro J. Hernández, Ciencia y Esperanza, Versión preliminar, agosto de 2005, http://www.geocities.com/pedroj.geo/cienciayesperanza.htm

7) Richard Dawkins, Son on Moore's Law, En The Next Fifty Years, Science in the First Half of the Twenty-First Century, edited by John Brockman, Vintage Books, Random House, New York, may 2002. 